\title{
The absence of a B allele in acquired B blood group phenotype confirmed by a DNA based genotyping method
}

\author{
S P Yip, W L Choy, C W Chan, C H Choi
}

\begin{abstract}
A case of an 87 year old woman with carcinomatous sigmoid colon, found to be of group $A_{1}$ with acquired $B$ status, is reported. The acquired $B$ phenotype was confirmed by the absence of a $B$ allele in the patient using denaturing gradient gel electrophoresis of a DNA fragment amplified from the ABO locus by the polymerase chain reaction.

(f Clin Pathol 1996;49:180-181)
\end{abstract}

Keywords: acquired B phenotype, PCR, denaturing gradient gel electrophoresis, DNA based genotyping method.

Group $A_{1}$ red cells may acquire B-like antigens in vivo by the action of bacterial deacetylases that convert $\alpha-\mathrm{N}$-acetyl-galactosamine (blood group A immunodominant sugar) into galactosamine. The latter is sufficiently similar to $\alpha$-galactose (blood group B immunodominant sugar) to cross react with polyclonal human anti-B reagents and some monoclonal anti-B reagents. ${ }^{1}$

The acquired $B$ phenotype can be diagnosed by serological ${ }^{1}$ and biochemical methods, ${ }^{2}$ the use of monoclonal antibodies, ${ }^{13}$ assay of serum transferase activities, and family studies. Since the cloning and sequencing of the gene encoding the ABO glycosyltransferase in $1990,{ }^{4}$ it is very easy to determine the genotypes at the $\mathrm{ABO}$ locus. In acquired $\mathrm{B}$ phenotype there should be no $\mathrm{B}$ allele at the $\mathrm{ABO}$ locus. This can be confirmed easily using DNA based genotyping methods. This short report describes the diagnosis of an acquired B phenotype by serological methods, which was confirmed by demonstrating the absence of a $\mathrm{B}$ allele using

Department of Health Science, Hong Kong

Polytechnic

University,

Hung Hom, Kowloon,

Hong Kong

S P Yip

Department of

Pathology, United

Christian Hospital,

130 Hip Wo Street,

Kwun Tong, Kowloon,

Hong Kong

W L Choy

C W Chan

C H Choi

Correspondence to:

Mr S P Yip.

Accepted for publication

26 July 1995

\section{Case report}

An 87 year old woman (KL) was admitted to hospital for sigmoid colectomy to excise carcinomatous sigmoid colon. Initially, 2 units of group A D+ donor blood were crossmatched. However, the grouping reactions were similar to those of a group $\mathrm{A}$ individual with the exception of a $1+$ mixed field reaction of the patient's red cells with reagent anti-B (CSL, Parkville, Australia). Before the resolution of the grouping anomaly, 4 units of group O D + blood were crossmatched on the day the operation was performed. The patient was not transfused during the operation. The patient was later transfused with two units of compatible group A D+ blood without any adverse effects. During this period, no bowel infection was documented. The patient was followed serologically for 11 days after surgery.

\section{Methods}

Antisera and reagent red cells were purchased from several different manufacturers (CSL, DBL (Dartmouth, Canada) and Dade (Miami, Florida, USA)). Serological investigations were performed using standard methods, ${ }^{1}$ and acidified anti-B was prepared according to Judd's method. ${ }^{5}$ DNA for polymerase chain reaction (PCR) was prepared, and PCR and denaturing gradient gel electrophoresis (DGGE) of amplified DNA fragments were carried out as described by Yip et al. ${ }^{6}$

\section{Results}

The patient's serological results (table) were typical of group $A_{1}$ with acquired $B$ antigen: positive reaction with anti- $B$, negative reaction with acidified anti-B, and presence of $A$ only in saliva. The patient's ABO genotype was found to be heterozygous $\mathrm{AO}$ : two homoduplex bands (AA and OO) and two heteroduplex bands (AO) were detected on DGGE (figure). No DNA band corresponding to the $\mathrm{B}$ allele was found (figure).

\section{Serological results}

Reagent antisera $\vee K L$ 's red cells

Anti-A

Anti-A,B

Acidified anti-B*

Anti-A (Dolichos biflorus) $\dagger$

Anti-H (Ulex europaeus)

Anti-D

Anti-Le ${ }^{a}$
Reagent red cells $\mathrm{v} K L$ 's serum

$A_{1}$ cells

B cells

Direct antiglobulin test

Saliva

(Anti-A dilutions $+\mathrm{KL}$ 's saliva) $v \mathrm{~A}_{1}$ cells

(Anti-A dilutions + saline) $v \mathrm{~A}_{1}$ cells

(Anti-B dilutions + KL's saliva) $v \mathrm{~B}$ cells

(Anti-B dilutions + saline) $v$ B cells

* The reaction of KL's cells with anti-B gradually increased to $2+\mathrm{mf}$ and finally to $4+$ during the study period until transfusion, while the reaction with acidified anti-B remained negative throughout the same period. $\mathrm{mf}=$ mixed field.

t The reaction of KL's cells with anti- $A_{1}$ became negative seven (see text). days after admission and remained negative until transfusion 


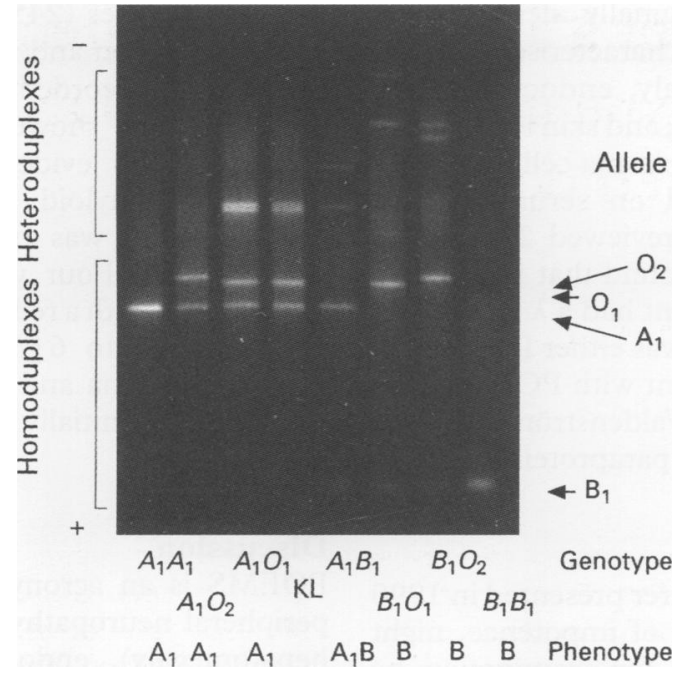

The determination of $A B O$ genotypes using denaturing gradient gel electrophoresis of polymerase chain reaction amplified $D N A$ fragments. The patient's $(K L)$ results are shown in parallel with control samples with known $A B O$ genotypes.

\section{Discussion}

This patient had a carcinomatous sigmoid colon and her serological results were indicative of an acquired $B$ phenotype in a group $A_{1}$ individual. Thus, both the clinical history and serological results of the patient were compatible with the presence of an acquired B phenotype. Our DNA genotyping method based on PCR followed by DGGE further demonstrated unequivocally that the patient did not possess a $\mathrm{B}$ allele at the $\mathrm{ABO}$ locus and was heterozygous AO.

The patient's red cells failed to react with anti- $A_{1}$ seven days after admission (table). One possible explanation for this is as follows: the anti- $A_{1}$ reaction is a function of the number of A sites per cell. $A_{1}$ cells have four to five times as many $A$ sites as $A_{2}$ cells. $^{78}$ The Dolichos biflorus lectin does react with $A_{2}$ cells, but is diluted to produce a negative result with $A_{2}$ cells in the reaction protocol. It reacts in saline tests because of the high $A$ site density in $A_{1}$ cells. ${ }^{8}$ In the case of acquired $B$ phenotype, the number of $A$ sites is reduced by deacetylation. The patient's cells were negative because the number of A sites was reduced below the critical level for the anti- $A_{1}$ to cause agglutination in saline tests.

This is the second report confirming the absence of a B allele in the acquired B phenotype using a DNA based genotyping method. The first such report used PCR followed by restriction analysis, but the patient's $\mathrm{ABO}$ genotype was not determined. ${ }^{9}$ Both reports demonstrated the usefulness of DNA based methods in confirming the absence of a B allele in the acquired $B$ phenotype, though slightly different PCR based methods were used.

S P Yip was supported by a research grant (340/667/A3/530) from the Department of Health Sciences, Hong Kong Polytechnic University, Hong Kong.

1 Walker RH, ed. Technical manual. 10th edn. Arlington, VA: American Association of Blood Banks, 1990.

2 Gerbal A, Ropars C, Gerbal R, Cartron JP, Maslet C, Salmon $C$. Acquired $B$ antigen disappearance by in vitro acetylation associated with $A_{1}$ activity restoration. Vox Sang 1976;31: 64-6.

3 Janvier D, Veaux S, Reviron M, Guignier F, Benbunan M. Serological characterization of murine monoclonal antibodies against acquired B red blood cells. Vox Sang 1990; 59:92-5.

4 Yamamoto F, Clausen H, White T, Marken J, Hakomori SI. Molecular genetic basis of the histo-blood group ABO system. Nature 1990;345:229-33.

5 Judd WJ. Methods in immunohematology. Miami: Montgomery Scientific Publications, 1988.

6 Yip SP, Yow CMN, Lewis WHP. DNA polymorphism at the ABO locus in the Chinese population of Hong Kong. Hum Hered 1995;45:266-71.

7 Voak D, Williams MA. An explanation of the failure of the direct antiglobulin test to detect erythrocyte sensitization in ABO haemolytic disease of the newborn and observations on pinocytosis of IgG anti-A antibodies by infant (cord) red cells. Br f Haematol 1971;20:9-23.

8 Williams MA, Voak D. Studies with ferritin-labelled Dolichos biflorus lectin on the numbers and distribution of $A$ sites on $A_{1}$ and $A_{2}$ erythrocytes, and on the nature of its specificity on $A_{1}$ and $A_{2}$ erythrocytes, and on the nature of its specificity
and enhancement by enzymes. $B r f$ Haematol 1972;23: and enhanc $427-41$.

9 Fisher GF, Faé I, Dub E, Pickl WF. Analysis of the gene polymorphism of ABO blood group specific transferases helps diagnosis of acquired B status. Vox Sang 1992;62: 113-16.

\title{
POEMS syndrome and Waldenström's macroglobulinaemia
}

\author{
S R Pavord, P T Murphy, V E Mitchell
}

\footnotetext{
Department of

Haematology,

Leicester Royal

Infirmary,

Leicester LE1 5 WW

Correspondence to:

Dr S Pavord.

Accepted for publication 1 June 1995
}

\begin{abstract}
A 58 year old man presented with a three year history of impotence, night sweats and ankle swelling. On examination, the patient fulfilled the diagnostic criteria for POEMS syndrome, but was unusual in that he also had underlying Waldenström's macroglobulinaemia with IgM $\kappa$ paraproteinaemia. The patient was treated with intermittent chlorambucil and made a good recovery. POEMS syndrome has been described in association with osteo-
\end{abstract}

sclerotic myeloma and Castleman's disease. The paraprotein involved is usually IgG or IgA with $\lambda$ light chains. This case indicates that the presence of $\lambda$ light chains is not essential for the pathogenesis of POEMS syndrome. It also emphasises the diversity of plasma cell dyscrasias that can manifest as POEMS syndrome.

(f Clin Pathol 1996;49:181-182)

Keywords: POEMS syndrome, Waldenström's macroglobulinaemia, IgM $\kappa$ paraproteinaemia. 